\section{Wilson Delgado Azañero' Hiroshi Concha Cusihuallpa ${ }^{1}$ Victor Calderón Ubaqui ${ }^{1}$}

Docente del Departamento Académico de Medicina Cirugía y Patología Oral. Facultad de Estoamtológia. Universidad Peruana Cayetano Heredia.

\section{Correspondencia}

Wilson A. Delgado Azañero

Av. Honorio Delgado 430 - Lima 31, Per Teléfono: (511) 381-1950 (252) e-mail:wdelgado@upch.edu.pe

\title{
Remisión espontánea de histiocitosis de células de Langerhans unifocal de la mandíbula
}

Delgado-Azañero W, Concha-Cusihuallpa H, Calderón-Ubaqui V. Remisión espontánea de histiocitosis de células de Langerhans unifocal de la mandíbula. Rev Estomatol Herediana. 2008; 18(1):35-43.

\section{RESUMEN}

La histiocitosis de células de Langerhans, denominada originalmente histiocitosis $\mathrm{X}$, comprende un grupo de desórdenes caracterizados por la proliferación anormal de este tipo de células acompañadas con abundante cantidad de esosinófilos. La enfermedad puede afectar cualquier estructura u órgano del cuerpo ya sea en forma localizada denominada granuloma eosinófilo o en formas sistémicamente diseminadas que dependiendo de la magnitud de las lesiones y edad del paciente reciben el nombre de enfermedad de Hand- Schuller-Christian o Letterer-Siwe. En este trabajo se presenta un caso de histiocitosis de células de Langerhans unifocal en una niña de 8 años de edad que había producido fractura patológica a nivel del cuerpo mandibular. La lesión se resolvió espontáneamente después de haber tomado una biopsia para diagnóstico y haber fijada la fractura. No se realizó ningún tratamiento adicional. Se presentan las características clínicas y radiográficas iniciales, la histología e inmunopatología de diagnóstico y los hallazgos a los 190 días de control.

Palabras clave: HISTIOCITOSIS DE CÉLULAS DE LANGERHANS / GRANULOMA EOSINÓFILO / ENFERMEDADES MAXILOMANDIBULARES.

Spontaneous remission of unifocal Langerhans cell histiocytosis of the manbible ABSTRACT

Langerhans'cell histiocytosis, formely known as histiocytosis X, comprises a group of disorders that implies an abnormal proliferation of these kind of cells and usually a massive aggregation of eosinophils. It affects any site and organ of the body, either as an isolated lesion, named eosinophilic granuloma, which is a localized form, or as a widespread systemic disease that correspond to Hand- Schuller-Christian and Letterer-Siwe diseases. We report a case of Langerhans?cell histiocytosis localized in the mandible of an 8-year-old girl which produced fracture of this bone. The lesion resolved spontaneously after a diagnostic biopsy and stabilization of the fracture No additional treatment was provided. The initial clinical and radiographic features, the histopathology and immunopatholy of the lesion and the evolution control after 190 days follow up of the case are presented.

Recibido : 15 de mayo del 2008

Aceptado : 19 de junio del 2008

Key words: LANGERHANS-CELL HISTIOCYTOSIS / EOSINOPHILIC GRANULOMA / JAW DISEASES.

\section{Introducción}

La histiocitosis de células de Langerhans es una entidad infrecuente cuya patogénesis se desconoce, está caracterizada por la proliferación local o diseminada de células dendríticas denominadas células de Langerhans, las cuales se originan y se encuentran normalmente en la médula ósea y también en el epitelio de la piel y de las mucosas incluyendo las encías (1). La célula de Langerhans pertenece al sistema fagocítico mononuclear pero es distinto al histiocito ya que su función es procesar y presentar antígenos, por lo tanto es parte del sistema inmunológico. Al estudio ultraestructural esta célula muestra gránulos intracitoplasmáticos específicos denominados gránulos de Birbeck, al examen de microscopía de luz su morfología muestra una célula de citoplasma amplio y pálido con núcleo lobulado e indentado, en la inmunohistoquímica se observa reacción positiva para antígeno S-100 y CD1a (2).

El desorden dependiente de la célula de Langerhans se denomina histiocitosis de células de Langerhans, la cual puede comprometer virtualmente cualquier sitio u órgano del cuerpo como lesión aislada o como enfermedad sistémica diseminada. Esta enfermedad fue originalmente denominada Histiocitosis X, término introducido por Lichtenstein en 1953, quien propuso que las enfermedades Letterer-Siwe, Hand Schüller Christian y granuloma eosinofílico eran diferentes manifestaciones de un mismo proceso patológico (3). A partir del año 1985, el término histiocitosis de células de Langerhans (HCL) ha re- emplazado prácticamente al de histiocitosis X.

Actualmente algunos autores utilizan la siguiente clasificación: 1. Forma crónica localizada de HCL, en la cual existe lesión ósea unifocal o multifocal denominada granuloma eosinofílico (GE); 2. Forma crónica diseminada que corresponde a la enfermedad de Hand Schüller Christian en la cual se encuentra diabetes insípida (poliurea), exoftalmia y compromiso visceral y óseo; 3. Forma diseminada aguda que corresponde a la enfermedad de Letterer-Siwe, la cual es considerada un proceso agresivo y grave que afecta principalmente a infantes de dos a tres años de vida y en donde se encuentra numerosas lesiones óseas, alteraciones cutáneas tipo eczema seborreica, hepatoesplenomegalia, anemia y linfadenopatía. 
De las tres formas señaladas, el granuloma eosinofilico es la lesión benigna más común estimándose que representa entre el 50 al $70 \%$ de todos los casos de HCL $(4,5)$. El GE ocurre más frecuentemente en niños, habiéndose señalado que aproximadamente el $75 \%$ de todos los pacientes son menores de 20 años de edad. Se manifiesta con lesiones óseas solitarias o múltiples que afectan principalmente los huesos planos como las costillas, las vértebras y los huesos del cráneo. El compromiso a nivel de las epífisis de los huesos largos es muy raro (6). Algunos autores han señalado que en pacientes menores de 20 años de edad los huesos maxilares son sitios frecuentes de manifestación de esta enfermedad (7). En la región de la cabeza se han reportado casos de GE en el hueso temporal (8-11), en el hueso occipital (2) en la región de la órbita ocular $(13,14)$ en el esfenoides (15); en la región del oído se han reportado casos que semejaban cuadros de otomastoiditis (16), también se han descrito casos de dolor cervical por la presencia de granuloma eosinofílico a nivel de vértebras cervicales $(17,18)$.

En la boca se han reportado casos con compromiso exclusivamente de la mucosa oral (19), pero el mayor número corresponde a los huesos maxilares con una o más lesiones distribuidas en uno o ambos maxilares, siendo el inferior el más afectado, donde generalmente las lesiones están ubicadas a nivel de premolares, molares y ángulo mandibular. En pocos casos se han reportado lesiones a nivel del cóndilo mandibular (20). Las lesiones de los maxilares pueden corresponder a una enfermedad unifocal o puede ser parte de un compromiso multifocal, donde además existen lesiones en otros huesos del cuerpo.

En los maxilares los síntomas más frecuentes son la presencia de una o varias masas palpables blandas que surgen del hueso con o sin dolor, deformación y desplazamiento de las tablas óseas corticales, aflojamiento de dientes, alvéolos postextracción que no cicatrizan, hiperplasia gingival con sagrado y ulceración. Ocasionalmente la evolución de la lesión ósea conduce a una fractura patológica (2124 ).

Desde el punto de vista radiográfico las lesiones de los maxilares aparecen como una o varias imágenes radiolúcidas no corticalizadas, mal definidas. Cuando existe destrucción del reborde alveolar el hueso parece excavado, en cambio cuando existe destrucción parcial del hueso alrededor de los dientes puede confundirse con cuadros de periodontitis. En los casos donde la destrucción ósea alveolar es completa, los dientes aparecen como " flotando en el aire" (25).Las alteraciones radiográficas no son patognomónicas y pueden confundirse con tumores óseos, cuadros de osteomielitis, tumores odontogénicos, granulomas de células gigantes y fibromas osificantes (26).

En un intento por correlacionar el cuadro clínico con la alteración radiográfica, Li y colaboradores (26) analizaron 20 casos de GE de los maxilares llegando a proponer que de acuerdo al sitio donde se desarrollan las lesiones pueden ser clasificadas en tres tipos:

- Tipo I o alveolar: las lesiones están confinadas al hueso alveolar.

- Tipo II o intraóseo: las lesiones están localizadas en el interior del hueso, fuera de la zona alveolar.

- Tipo III o mixto: las lesiones comprometen el interior y la zona alveolar de hueso.

En la lesiones Tipo I o alveolar el paciente presenta dolor y movilidad de dientes, asociado con síntomas de enfermedad periodontal como son sangrado, hinchazón y ulceración de las encías, radiográficamente se observa destrucción del hueso alveolar en forma similar a la reabsorción ósea de la periodontitis. En la lesión severa el hueso de soporte de los dientes está perdido, produciéndose desplazamiento de los dientes involucrados dando una imagen radiográfica de diente flotando.

En la lesión Tipo II o intraósea el síntoma más común es hinchazón con o sin dolor de la zona ósea comprometida. Radiográficamente se observa una lesión central destructiva de apariencia agresiva, con expansión de tablas óseas, reacción periostal, osteolisis difusa que sugiere tumor maligno u osteomielitis. En algunos casos pueden observarse imágenes quísticas y multiquísticas.

En la lesión Tipo III o mixta se observan una mezcla de síntomas y cambios radiográficos señalados para la lesión Tipo I y II. Radiográficamente no se puede establecer en qué tipo se originó la lesión.

En el examen histológico las lesiones óseas se caracterizan por la presencia de una infiltración difusa de células mononucleares grandes, de límites no bien definidos, de citoplasma pálido, con un núcleo vesicular indentado o redondeado. Entremezclados con estas células parecidas a histiocitos, existen eosinófilos en cantidades variables. También se observan plasmocitos, linfocitos y células gigantes multinucleadas y con frecuencia existen áreas de necrosis y hemorragia (25). Debido a que las células de Langerhans en preparados histológicos de rutina pueden fácilmente confundirse con histiocitos, para su confirmación es necesaria la identificación de los gránulos de Birbeck en el citoplasma de las células por medio de microscopía electrónica o por inmunohistoquímica utilizando la proteina S-100 o anticuerpos contra CD-1a . 
La HCL localizada (granuloma esosinofilico localizado) tiene un curso clínico generalmente benigno y en muchos casos se resuelve espontáneamente en periodos de meses a años después de haber sido sometida a una biopsia de diagnóstico. Las lesiones grandes, dolorosas, con riesgo de fractura han sido controladas empíricamente con quimioterapia, curetajes quirúrgicos conservadores, radioterapia a bajas dosis e inyecciones intralesionales de corticosteroides (27, 28). La radioterapia, si bien controla el dolor, no produce remisión completa de las lesiones.

En relación con la quimioterapia se han utilizado por un lado inmunomoduladores y por otro lado drogas citotóxicas habiéndose obtenido resultados variables con el uso de 2-deoxicoformin, etoposide, vinblastina, mercaptopurina, metrotrexate, prednisolona, interferon e interleucina (23). En cambio, en lesiones solitarias se han reportado, excelentes resultados después de inyecciones intralesionales de triancinolona (22) y con una sola inyección de metilprednisolona (28). Todavía no se conoce la forma como actúa la corticoterapia, no se sabe si el esteroide suprime la proliferación de las CL, de los linfocitos T, de los esosinófillosos o por el contrario estimula la osteogénesis.

En la literatura se encuentran varios reportes de remisión espontánea de HCL , incluyendo la enfermedad de Letterer-Siwe. Los reportes de casos de los maxilares que han remitido espontáneamente son muy escasos, correspondiendo la mayoría de reportes a lesiones que se han desarrollado en otros huesos. En el año 1991 se reportó un caso bifocal que comprometía la mandíbula y la maxila que regresionó espontáneamente después de la biopsia y de extracciones dentales (29).En el año 2001 se reportó un caso a nivel de la mandíbula (30), en el año 2004 tres casos, uno correspondiente al maxilar superior y dos a la mandíbula (31) y en el año 2005 se reportó un caso con lesiones en la mandíbula y en la mucosa palatina, en donde estas últimas regresionaron espontáneamente. (32)

El objetivo de este trabajo es reportar un caso de HCL unifocal localizado en el cuerpo de la mandíbula que remitió espontáneamente después de la toma de una biopsia con fines de diagnóstico.

\section{Reporte del caso}

Paciente niña de 8 años de edad referida al servicio de Medicina y Patología Oral y Maxilofacial de la Facultad de Estomatología de la UPCH por "inflamación de la encía" del cuarto cuadrante, acompañada de dolor a nivel mandibular que se incrementaba durante la masticación. La enfermedad se había iniciado hace dos meses con dolor, movilidad de la pieza 46 y aparentemente con secreción purulenta, por lo que la paciente recibió antibióticos por dos semanas y luego le extrajeron el diente. Durante la anamnesis no se encontró antecedentes personales ni familiares de importancia y la revisión de aparatos y sistemas no evidenció alteraciones.

Examen clínico

El examen clínico general mostraba una niña en aparente buen estado de salud que presentaba asimetría facial por un abultamiento de la mandíbula que se extendía desde la región parasinfisiaria derecha hasta cerca del ángulo del maxilar (Fig.1). Intraoralmente se observaba un tumor de consistencia blanda que reemplazaba la tabla vestibular extendiéndose desde la pieza 84 hasta la 47 , a la palpación se evidenciaba crepitación en el fondo del surco. La mucosa aparecía enrojecida y en la zona de la pie-

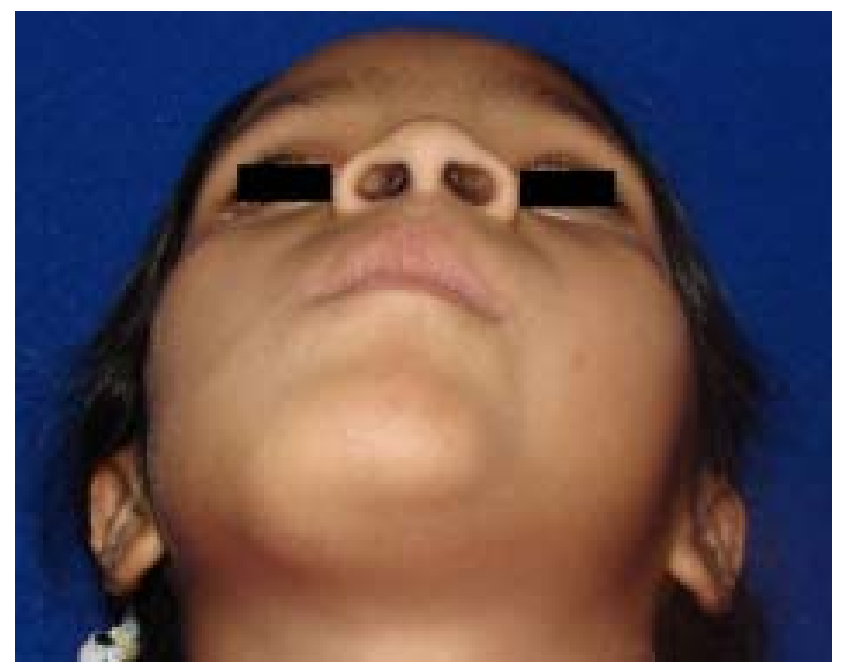

Fig. 1. Abultamiento de la zona parasinfisiaria y cuerpo de la mandíbula derecha.

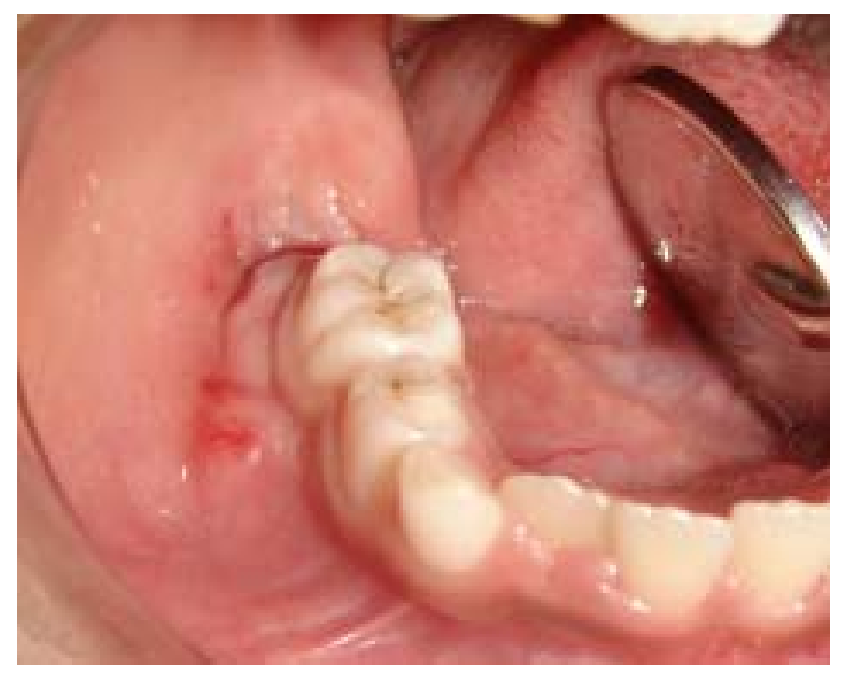

Fig. 2. Tumor que ocupa el fondo del surco vestibular cubierto por mucosa eritematosa. Alvéolo no cicatrizado de la pieza 46. 
za 46 se observaba una úlcera correspondiente al alveolo no cicatrizado (Fig.2). La exploración del cuerpo mandibular indicaba la presencia de una fractura patológica a nivel de la pieza 46. Durante la manipulación de los tejidos, la niña manifestaba dolor. También se detectaron 3 adenopatías submaxilares bilaterales de $1 \mathrm{~cm}$. de diámetro que fueron consideradas de carácter inflamatorio.

\section{Estudio radiográfico}

La radiografía panorámica (Fig.3) mostraba una extensa imagen radiolúcida que ocupaba toda la altura del cuerpo mandibular extendiéndose desde de la pieza 43 hasta la cara mesial de la pieza 47, el borde óseo basal estaba adelgazado y los gérmenes dentarios de las piezas 43, 44 y 45 se observaban sin criptas óseas, igualmente en la radiografía periapical se observaba desaparición del hueso alveolar de la pieza 85 (Fig.4).

En la radiografía oclusal se observaba un marcado adelgazamiento de las corticales vestibular y lingual, con zonas de pérdida de hueso, que evidenciaba la presencia de fractura patológica, también se podía distinguir radiolucideces con patrón de madera apolillada (Fig.5). Estos cambios radiográficos eran compatibles con una neoplasia maligna.

\section{Otros estudios}

La gammagrafía con Tc 99 mostró hipercaptación de esta sustancia a nivel del cuerpo mandibular derecho (Fig.6), el resto del esqueleto estaba normal lo que descartaba una patología multifocal. Los estudios para glucosa, calcio, fósforo inorgánico, fosfatasa alcalina, paratohormona, cortisol basal y cortisol 60' post ACTH mostraron valores normales, tampoco se encontraron alteraciones en el hemograma.

Estudio histopatológico

En la biopsia obtenida de la lesión se observaban mantos de células mononucleares de citoplasma amplio

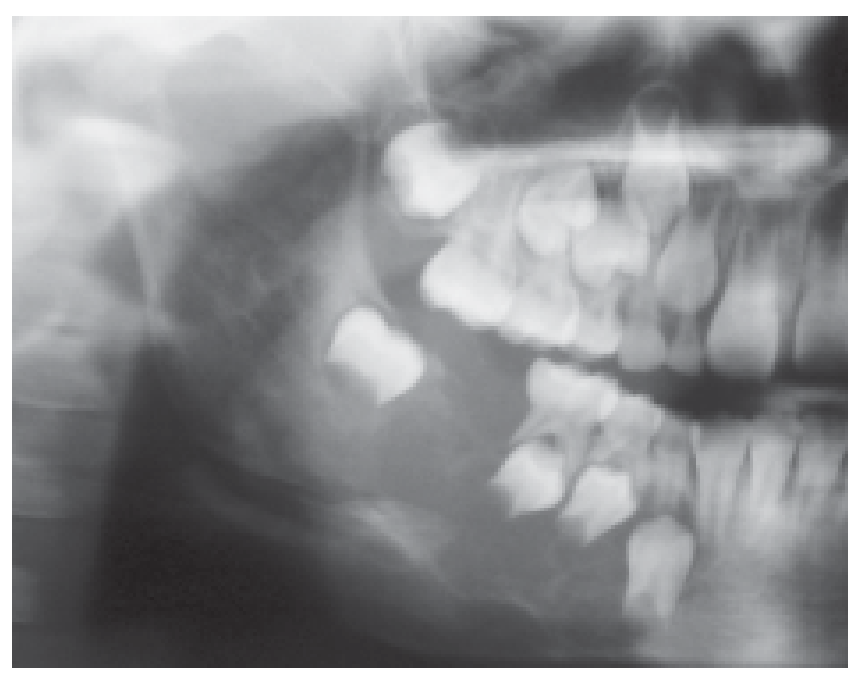

Fig. 3. Imagen radiolúcida no corticalizada del cuerpo del maxilar. Adelgazamiento de la cortical basal y ausencia de criptas óseas de 43,44 y 45.

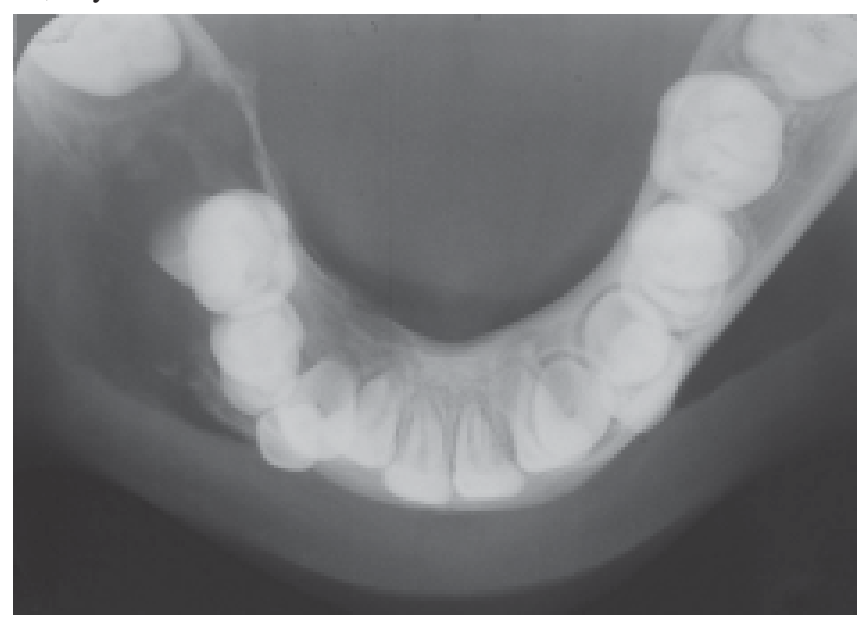

Fig. 5. Vista de la lesión en radiografía oclusal. Nótese las perforaciónes de las tablas vestibular y lingual que corresponden a la fractura patológica.

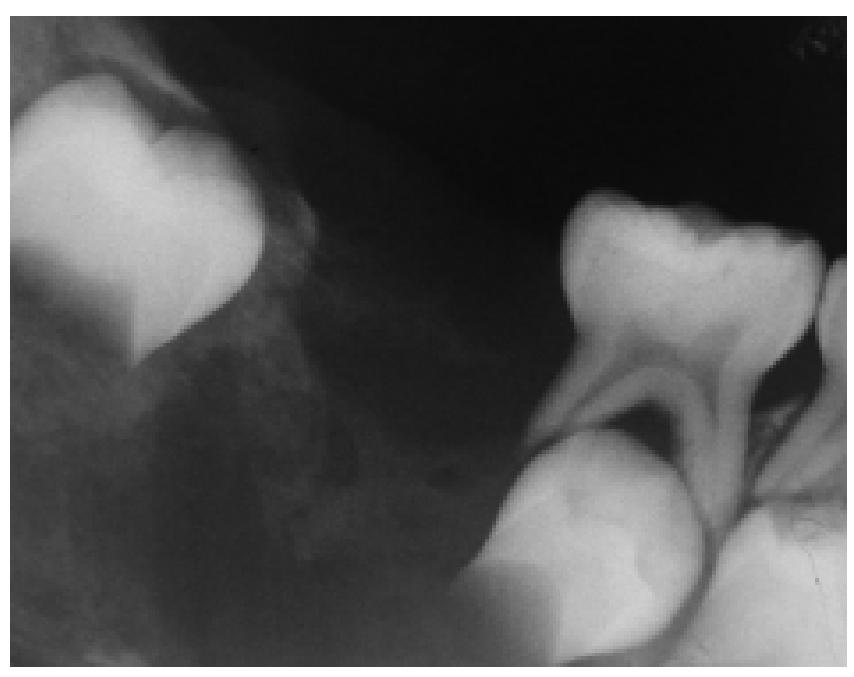

Fig. 4. Detalles de la imagen radiolúcida vista en una radiografía periapical. Nótese la ausencia de hueso alveolar de la pieza 85.

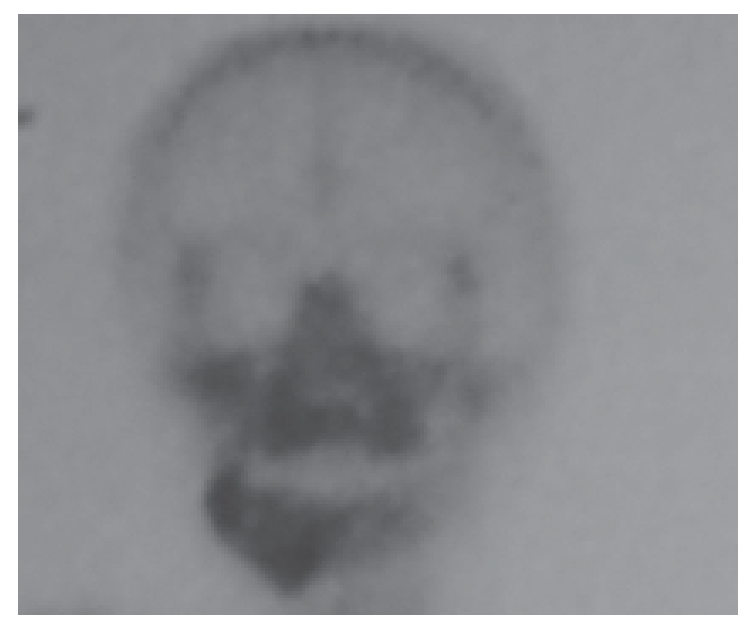

Fig. 6. Gammagrafía ósea donde se observa hipercaptación de la sustancia radioactiva en el cuerpo del maxilar. 
y claro con núcleo indentado o en forma de grano de café, entremezcladas con abundante cantidad de la eosinófilos y células gigantes multinucleadas(Fig.7). También se distinguían linfocitos, células plasmáticas y escasos polimorfonucleares. En algunas áreas existía abundante cantidad de células gigantes multinucleadas dentro de un estroma muy vascularizado similar al cuadro histológico del granuloma central de células gigantes (Fig. 8). El estudio inmunohistoquímico mostró marcada reacción positiva para proteina S-100 a nivel del núcleo y del citoplasma de las células mononucleares (Fig. 9) pero no en las células gigantes multinucleadas (Fig.10).

Diagnóstico

El resultado del estudio histológico e inmunohistoquímico más los cambios óseos observados en las radiografías y gammagrafía estableció el diagnóstico definitivo de histiocitosis de células de Langerhans unifocal localizadoen el maxilar inferior derecho.

\section{Evolución}

A partir del día de la toma de la biopsia el paciente recibió antibióticoterapia como medida preventiva contra infección, consistente en amoxicilina 500mg cada 8 horas durante 10 días, además de ibuprofeno 200mg cada 8 horas supeditado a la presencia de dolor.En la tercera semana se observó una reducción notoria de la tumefacción del cuerpo mandibular derecho pero persistía la movilidad de los fragmentos óseos correspondientes a la fractura mandibular. Para entonces ya se había establecido el diagnóstico definitivo y se decidió esperar una remisión

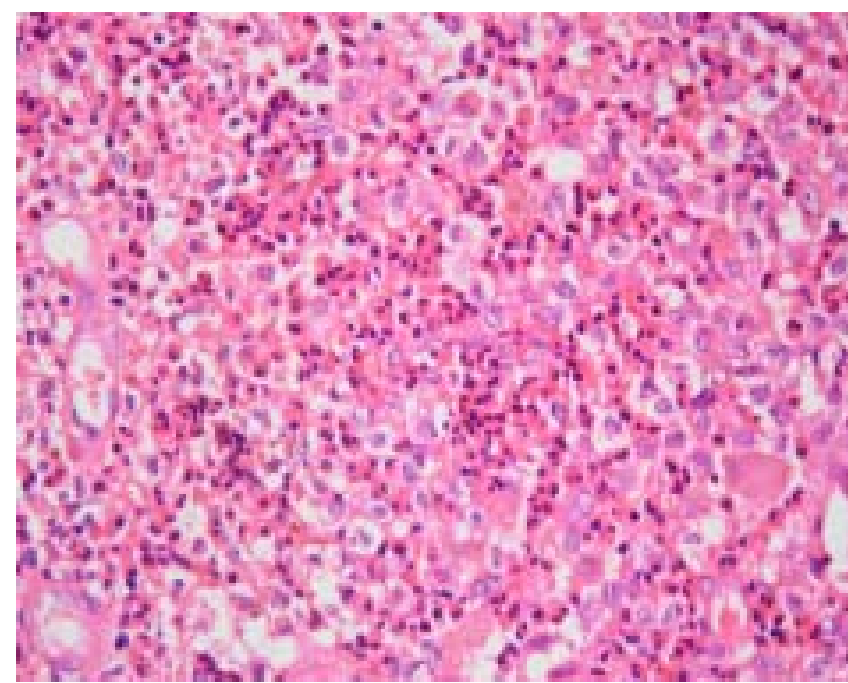

Fig. 7. Células monocucleares de citoplasma claro, límites no definidos y núcleo indentado (C.deLangerhans),entremezcladas con abundante cantidad de eosinólilos. H\&E. 400X.

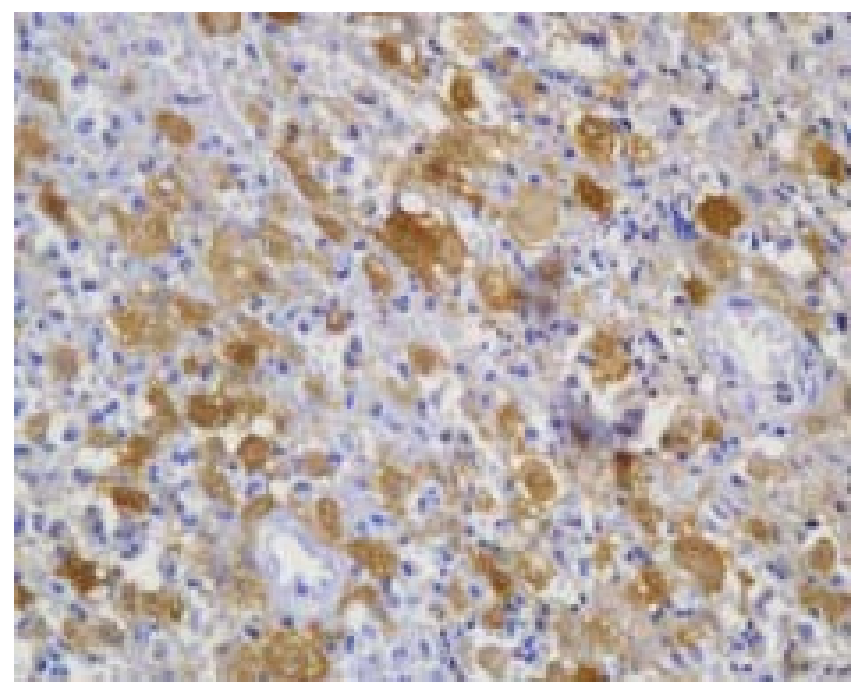

Fig. 9. Reacción positiva en el citoplasma y núcleo de las células de Langerhans a la proteína S-100. 400X.

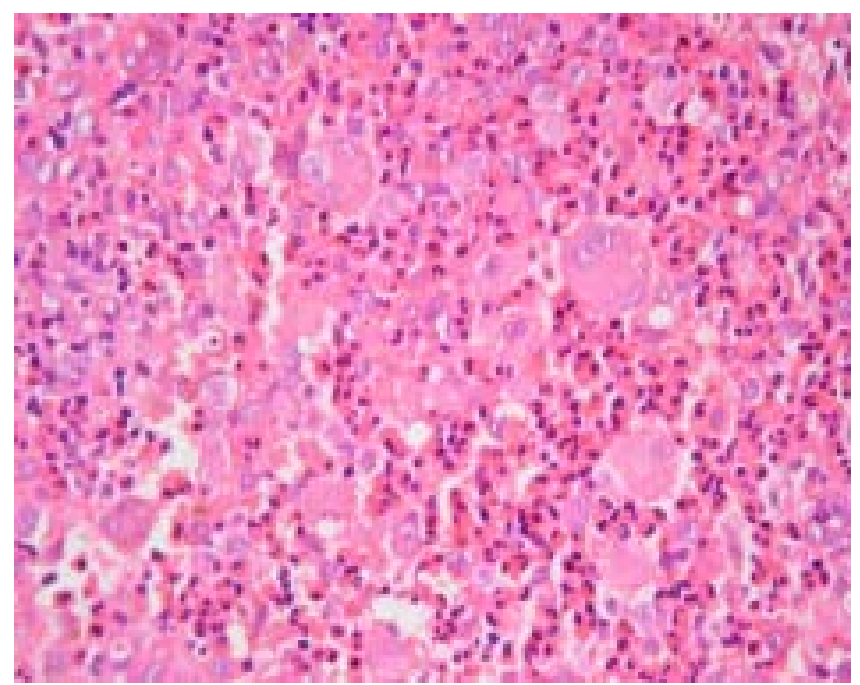

Fig. 8. Células de Langerhans, esosinófilos y numerosas células gigantes multinucleadas. H\&E. 400X.

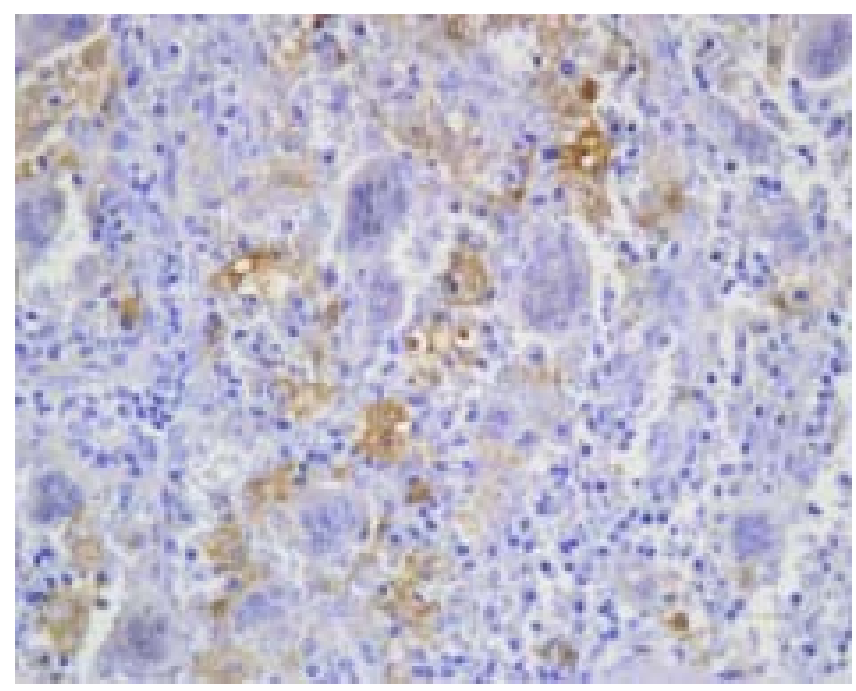

Fig. 10. Numerosas células gigantes multinucleadas, con reacción negativa para S-100. Inmunoreacción positiva para las células de Langerhans. 400X. 
espontánea de la lesión, procediéndose únicamente a realizar fijación intermaxilar con tornillos y alambre, que inmovilizó la mandíbula y permitió mantener la oclusión dental estable. Nuevamente de indicó $500 \mathrm{mg}$ de amoxicilina durante 10 días.En las siguientes semanas la disminución de la tumefacción vestibular era marcada y la consistencia, inicialmente blanda, ahora mostraba dureza, el dolor había disminuido progresivamente. A los 21 días de la fijación intermaxilar se comprobó una disminución considerable de la movilidad de los segmentos fracturados, decidiéndose liberar la fijación intermaxilar dejando a la paciente con apertura bucal funcional. Durante todo el tratamiento la paciente recibió complemento nutricional a base de concentrados proteicos.

El control radiográfico a las cuatro semanas mostraba inicio de regeneración ósea a nivel de la lesión central, basal mandibular, criptas óseas de los gérmenes dentales y en la cortical lingual y vestibular

Control a los 190 días después de la toma de la biopsia.

En el examen clínico se encontró una notable disminución de la deformación del cuerpo mandibular, la mucosa vestibular aparecía normal y el alveolo había cicatrizado (Figs. 11 y
12). En las radiografías se observaba una evidente regeneración ósea en toda la lesión incluyendo a la basal mandibular y a las corticales vestibular y lingual, pero el grosor de estas tablas faltaba completarse. Las criptas óseas de los gérmenes dentales de la piezas 43,44 y 45 se habían recuperado y estos dientes se encontraban en proceso de erupción normal; la fractura mandibular estaba completamente consolidada (Fig.13 y 14)

En la actualidad la paciente se encuentra asintomática, en buen estado general, sus funciones vitales están normales, la oclusión dental está conservada y continua bajo control clíni-

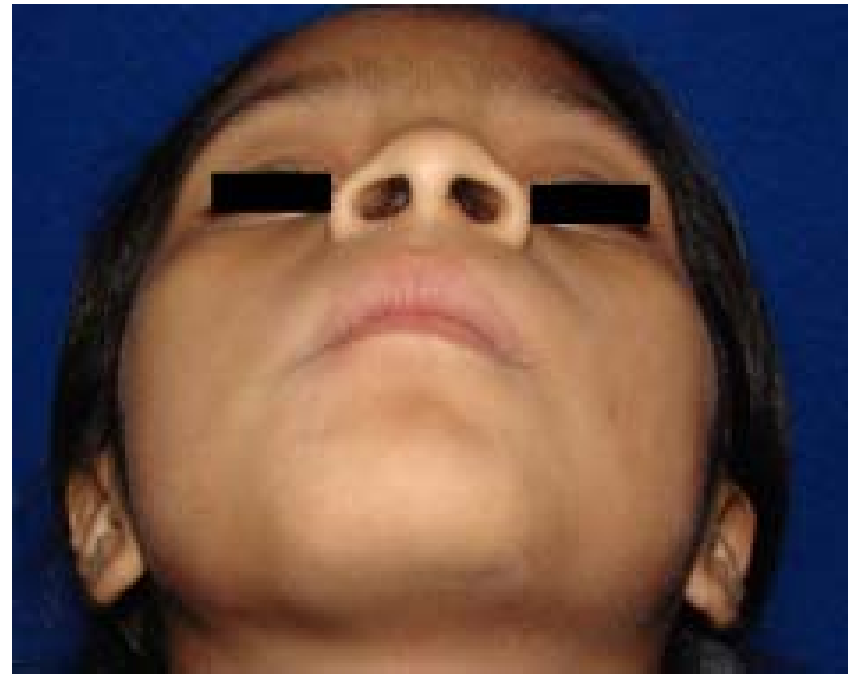

Fig. 11. Control a los 190 días. Se distingue una ligera deformación de la zona parasinfisiaria.

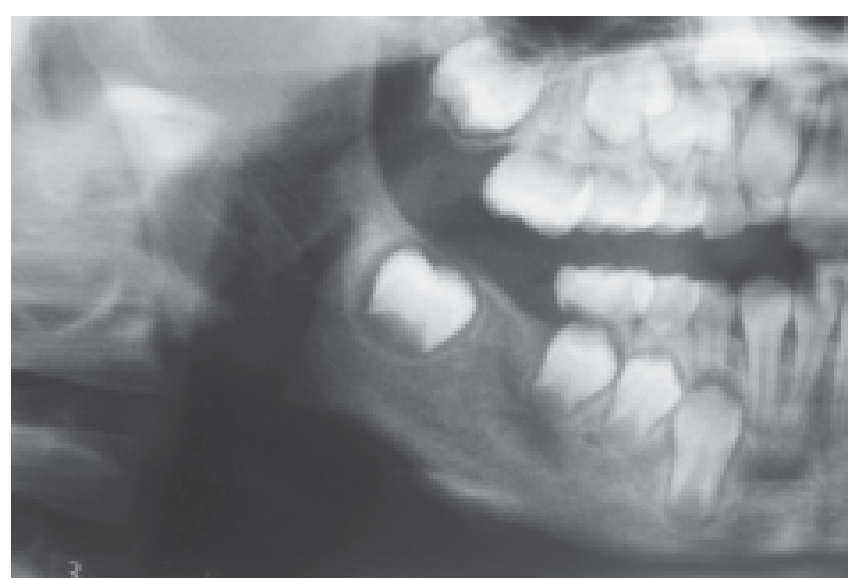

Fig. 13. Control a los 190 días: marcada neoformación ósea que ha reemplazado la lesión del cuerpo del maxilar y recuperado las criptas óseas de 43,44 y 45.

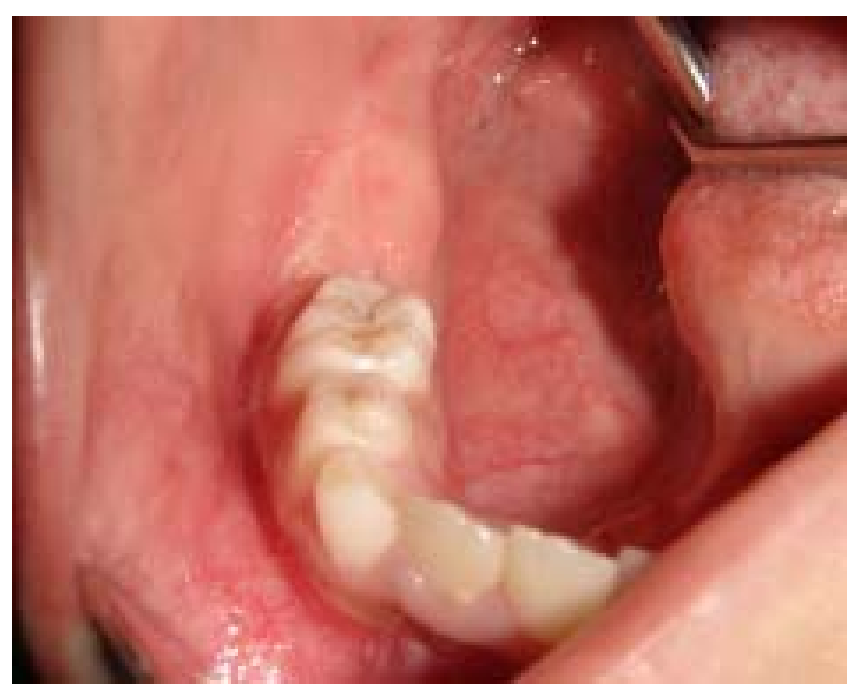

Fig. 12. Control a los 190 días. Surco vestibular normal, el alveolo de la pieza 46 esta cicatrizado.

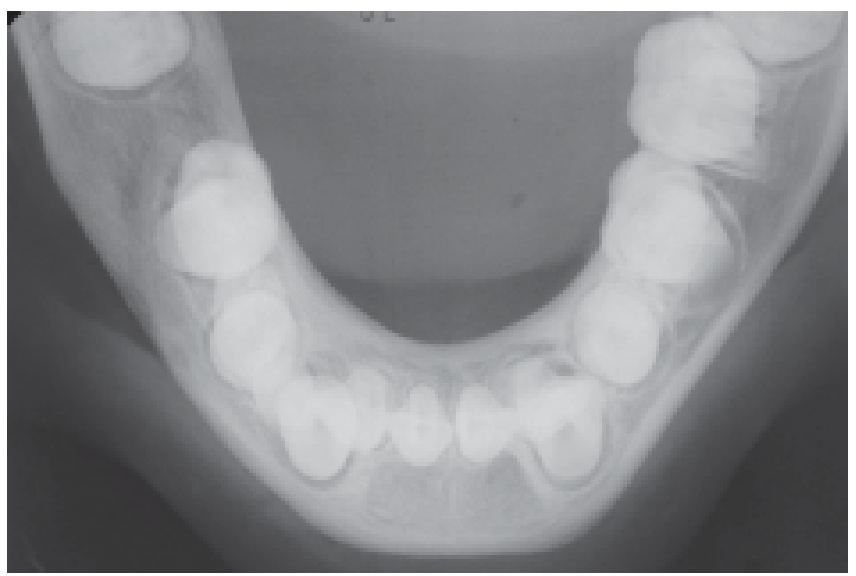

Fig. 14. Control a los 190 días, la rx oclusal muestra reparación de la fractura, corticales vestibular y lingual con signos de neoformación y remodelado óseo. 
co y radiográfico periódico.

\section{Discusión}

La histiocitosis de células de Langerhans es una enfermededad producida por la proliferación clonal de las células de Langerhans, afecta cualquier órgano o estructura del cuerpo humano manifestándose de diversas formas, siendo tres los principales cuadros clínicos: 1. Histiocitosis de células de Langerhans localizada, donde puede existir lesión ósea unifocal o multifocal denominada granuloma eosinofílico; 2. Forma crónica diseminada o enfermedad de Hand-SchüllerChristian en la cual se encuentra diabetes insípida (poliurea), exoftalmia y compromiso visceral y óseo y 3 . Forma diseminada aguda o enfermedad de Letterer-Siwe, cuyo curso es agresivo y grave, afecta principalmente a infantes de dos a tres años de vida y se manifiesta con lesiones óseas numerosas, alteraciones cutáneas tipo eczema seborreica, hepatoesplenomagalia, anemia y linfadenopatía.

Como se ha señalado, en la región maxilofacial la enfermedad puede manifestarse con una amplia gama de cuadros clínicos y las imágenes radiográficas de las lesiones óseas de los huesos maxilares corresponden a áreas osteolíticas de diverso tamaño, forma y ubicación que en ningún caso se pueden considerar patognomónicas de HCL.

Cuando se establece el diagnóstico de histiocitosis de células de Langerhans en cualquier zona anatómica del cuerpo es fundamental realizar en el paciente un estudio radiográfico y gammagráfico óseo completo que determinará si se trata de una lesión unifocal o multifocal. Estos resultados unidos a la edad del paciente, ubicación de las lesiones y al grado de compromiso de las estructuras u órganos involucrados determi- nará el tipo de tratamiento.

En los casos que exista compromiso múltiple de órganos y huesos el tratamiento estará a cargo del oncólogo y en los casos de pacientes niños del pediatra y del oncólogo. En el caso de HCL localizado, denominado granuloma eosinofílico unifocal, las lesiones óseas son solitarias y el tratamiento puede ser curetaje óseo, infiltraciones intralesionales de corticoides, biopsia y curetaje o simplemente biopsia para diagnóstico y observación de la evolución de la lesión. El uso de la radioterapia está confinado a lesiones ubicadas en órganos vitales (33). Es importante señalar que remisión espontánea de la enfermedad se ha reportado no solamente en lesiones unifocales sino también en casos multifocales (34)

En el presente caso el estudio radiográfico y la gammagrafía ósea, demostraron que se trataba de una lesión única ubicada a nivel del cuerpo del maxilar inferior. Si se aplica la clasificación de Li et al. (26), el cuadro clínico y radiográfico corresponde al Tipo III o mixto, es decir, existe destrucción del hueso alveolar y de la parte central de la mandíbula, complicada con fractura patológica.

El diagnóstico se estableció mediante estudio histológico de una biopsia obtenida de la lesión ósea, donde las coloraciones de rutina mostraban cambios morfológicos típicos atribuidos a histiocitosis de células de Langerhans, por otro lado la identificación de estas células fue posible por su fuerte reactividad a la proteína S100 (Fig. 9). Es interesante destacar la abundante cantidad de células gigantes presentes en la lesión que pudo llevar a confundirla con un granuloma central de células gigantes, en este sentido es importante señalar que fue de gran ayuda la inmunohistoquímica ya que éstas células no son reactivas a S-100, destacandose nítidamente entre las células de Langerhans (Fig.10).

El estudio radiográfico de control realizado a los 190 días demostró la gran regeneración ósea que se produjo espontáneamente en todas las parte de la lesión, incluyendo la neoformación de las criptas óseas de los gérmenes dentales, así como el remodelado del hueso que condujo a la recuperación de la morfología de las tablas óseas, también es importante resaltar que el proceso de erupción dental no sufrió alteración notándose el desarrollo de los gérmenes y la reabsorción de las raíces de los dientes decíduos (Fig. 13).

La rápida neoformación ósea que se observó en este caso incluyendo la consolidación de la fractura patológica probablemente se debió a la edad de la paciente y a la fijación intermaxilar, por otro lado, no sabemos si la antibióticoterapia y la ingesta de concentrados proteínicos en la dieta influenciaron en la excelente evolución de la lesión.

La remisión espontánea de HCL ha sido reportado en casos que han afectado diversos huesos del cuerpo, los reportes de casos a nivel de los maxilares son escasos (29-32), en todos ellos la regeneración ósea se produjo después de la toma de biopsias de diagnóstico. Por otro lado es importante señalar que remisión espontánea de la enfermedad se ha reportado no solamente en lesiones unifocales sino también en casos multifocales (34).

La regresión espontánea de las lesiones óseas de HCL es un fenómeno biológico que por ahora no tiene una explicación. Se ha sugerido que las células que componen la lesión se encuentran en estado de inmadurez y que posiblemente el trauma producido por la biopsia o el curetaje inducen la maduración celular, resultando en la resolución de la enfermedad (31). 
El hecho que en la lesión, además de células de Langerhans, que son procesadoras de antígenos, existen eosinófilos, células gigantes multinucleadas, neutrófilos y pequeños linfocitos, sugiere que posiblemente se trata de una lesión reactiva a un antígeno desconocido, incluyendo partículas virales y por lo tanto la biopsia o el curetaje óseo estimularía una respuesta inflamatoria que conduce a la regresión de la lesión como consecuencia del fenómeno de reparación de los tejidos. Por otro lado, todavía no se conocen todas las funciones que tienen los eosinófilos, células que se encuentran en otra lesión que también cura espontáneamente como es la úlcera eosinofílica (35).

Probablemente un mejor entendimiento de la función de cada una de las células presentes en las lesiones de HCL pueda explicar en el futuro la remisión espontánea de estas lesiones, así como otras características del comportamiento biológico de esta infrecuente entidad.

Finalmente, este reporte contribuye con un caso más al concepto actualmente en boga que la HCL localizada es una entidad que definitivamente cura espontáneamente y por lo tanto, una conducta conservadora es el tratamiento correcto.

\section{Referencias bibliográficas}

1. Broadbent V, Egeler RM, Nesbit ME Jr. Langerhans cell histiocytosis--clinical and epidemiological aspects. Br J Cancer Suppl. 1994; 23:S11-6.

2. Lieberman PH, Jones CR, Steinman RM, Erlandson RA, Smith J, Gee T, Huvos A, GarinChesa P, Filippa DA, Urmacher $\mathrm{C}$, Gangi MD, Sperber M. Langerhans cell (eosinophilic) granulomatosis. A clinicopathologic study encompassing 50 years. Am J
Surg Pathol. 1996; 20(5):519-52.

3. Lichtenstein L. Histiocytosis X; integration of eosinophilic granuloma of bone, LettererSiwe disease, and SchüllerChristian disease as related manifestations of a single nosologic entity. AMA Arch Pathol. 1953;56(1):84-102.

4. Roychoudhury A, Shah N, Parkash H, Mukhopadhyay S, Chopra P. Eosinophilic granuloma of the jaws. Br J Oral Maxillofac Surg. 1998; 36(5):380-3.

5. Key SJ, O'Brien CJ, Silvester KC, Crean SJ. Eosinophilic granuloma: resolution of maxillofacial bony lesions following minimal intervention. Report of three cases and a review of the literature. J Craniomaxillofac Surg. 2004; 32(3):170-5.

6. Caballes RL, Caballes RA Jr, McKeon JJ. Langerhans cell histiocytosis involving epiphysis of a long bone. Ann Diagn Pathol. 2004; 8(2):91-5.

7. Schajowicz F. Eosinophilic granuloma. In: Schajowicz X, Editor. Tumors and tumor like lesions of bone; pathology, radiology and treatment. New York: Springer; 1994. p.552-566.

8. Akisada T, Harada T, Yoshihiro $\mathrm{T}$, Kawai A. A case of bilateral eosinophilic granuloma in the temporal bone. Auris Nasus Larynx. 1999; 26(3):343-8.

9. Bayazit Y, Sirikci A, Bayaram M, Kanlikama M, Demir A, Bakir K. Eosinophilic granuloma of the temporal bone. Auris Nasus Larynx. 2001; 28(1):99-102.

10. Yetiser S, Karahatay S, Deveci $\mathrm{S}$. Eosinophilic granuloma of the bilateral temporal bone. Int $\mathrm{J}$ Pediatr Otorhinolaryngol. 2002; 62(2):169-73.
11. Saliba I, Sidani K, El Fata F, Arcand P, Quintal MC, Abela A. Langerhans' cell histiocytosis of the temporal bone in children. Int J Pediatr Otorhinolaryngol. 2008; 72(6):775-86.

12.Fujimura $M$, Nishijima $M$, Umezawa K, Hayashi T, Kaimori M. A case of calvarial eosinophilic granuloma with rapid expansion and wide skull invasion: immunohistochemical analysis of Ki-67. J Clin Neurosci. 2002; 9(1):72-6.

13.Petridis A, Giannopoulos T, Anastasiadou K, Sidiropoulou M, Palladas P. Solitary Langerhans cell histiocytosis of the orbital wall. Eur J Radiol Extra. 2004; 51(3):95-7.

14.Gündüz K, Palamar M, Parmak N, Kuzu I. Eosinophilic granuloma of the orbit: report of two cases. J AAPOS. 2007; 11(5):506-8.

15. Krishna H, Behari S, Pal L, Chhabra AK, Banerji D, Chhabra DK, Jain VK. Solitary Langerhans-cell histiocytosis of the clivus and sphenoid sinus with parasellar and petrous extensions: case report and a review of literature. Surg Neurol. 2004; 62(5):447-54.

16. Jonas N, Mulwafu W, Khosa SA, Hendricks M. Case study: Langerhans' cell histiocytosis (LCH). Int J Pediatr Otorhinolaryngol Extra. 2008; 3(2):61-5.

17.Simanski C, Bouillon B, Brockmann M, Tiling T. The Langerhans' cell histiocytosis (eosinophilic granuloma) of the cervical spine: a rare diagnosis of cervical pain. Magn Reson Imaging. 2004; 22(4):589-94.

18.Per H, Koç KR, Gümüs? H, Canpolat M, Kumandas? S. Cervical Eosinophilic Granuloma and 
Torticollis: A Case Report and Review of the Literature. J Emerg Med. Forthcoming 2008.

19. Milián MA, Bagán JV, Jiménez Y, Pérez A, Scully C, Antoniades D. Langerhans' cell histiocytosis restricted to the oral mucosa. Oral Surg Oral Med Oral Pathol Oral Radiol Endod. 2001; 91(1):76-9.

20. Miyamoto H, Dance G, Wilson DF, Goss AN. Eosinophilic granuloma of the mandibular condyle. J Oral Maxillofac Surg. 2000; 58(5):560-2.

21. Holzhauer AM, Abdelsayed RA, Sutley SH. Eosinophilic granuloma: a case report with pathologic fracture. Oral Surg Oral Med Oral Pathol Oral Radiol Endod. 1999; 87(6):756-9.

22.Watzke IM, Millesi W, Kermer C, Gisslinger H. Multifocal eosinophilic granuloma of the jaw: long-term follow-up of a novel intraosseous corticoid treatment for recalcitrant lesions. Oral Surg Oral Med Oral Pathol Oral Radiol Endod. 2000; 90(3):317-22.

23.Eckardt A, Schultze A. Maxillofacial manifestations of Langerhans cell histiocytosis: a clinical and therapeutic analysis of 10 patients. Oral Oncol. 2003; 39(7):687-94.

24.dos Anjos Pontual ML, da Silveira MM, de Assis Silva Lima
F, Filho FW. Eosinophilic granuloma in the jaws. Oral Surg Oral Med Oral Pathol Oral Radiol Endod. 2007; 104(6):e47-51.

25. Neville BW, Damm DD, Allen CM, Bouquot JE. Editors Oral \& Maxillofacial Pathology. 2nd ed. Philadelphia: Saunders; 2002. p. 513-4.

26.Li Z, Li ZB, Zhang W, Li JR, Wang SP, Cheng Y, Wei MX. Eosinophilic granuloma of the jaws: an analysis of clinical and radiographic presentation. Oral Oncol. 2006; 42(6):574-80.

27. Jones LR, Toth BB, Cangir A. Treatment for solitary eosinophilic granuloma of the mandible by steroid injection: report of a case. J Oral Maxillofac Surg. 1989; 47(3):306-9.

28.Putters TF, de Visscher JG, van Veen A, Spijkervet FK. Intralesional infiltration of corticosteroids in the treatment of localised langerhans' cell histiocytosis of the mandible Report of known cases and three new cases. Int J Oral Maxillofac Surg. 2005; 34(5):571-5.

29. Gnanasekhar JD, Ahmad MS, Reddy RR. Multifocal Langerhans cell histiocytosis of the jaws: a case report. Quintessence Int. 1991; 22(7):559-64.

30. Namai T, Yusa H, Yoshida H.
Spontaneous remission of a solitary eosinophilic granuloma of the mandible after biopsy: a case report. J Oral Maxillofac Surg. 2001; 59(12):1485-7.

31.Key SJ, O'Brien CJ, Silvester KC, Crean SJ. Eosinophilic granuloma: resolution of maxillofacial bony lesions following minimal intervention. Report of three cases and a review of the literature. J Craniomaxillofac Surg. 2004; 32(3):170-5.

32. Schroff J. Eosinophilic granuloma of bone: case report of eosinophilic granuloma of mouth (jaws, gums, and palate) with simultaneous fistula in ano. 1948. Oral Surg Oral Med Oral Pathol Oral Radiol Endod. 2005; 100 (2 Suppl):S37-41.

33.Ladisch S, Gadner H. Treatment of Langerhans cell histiocytosis-evolution and current approaches. Br J Cancer Suppl. 1994; 23:S41-6.

34. Broadbent V, Pritchard J, Davies EG, Levinsky RJ, Heaf D, Atherton DJ, Pincott JR, Tucker S. Spontaneous remission of multi-system histiocytosis X. Lancet. 1984; 1(8371):253-4.

35.Delgado W, Funes I. Ulcera eosinofílica de la lengua. Rev Estomatol Herediana 2004; 13(12):36-39. 